\title{
Impulsivity and Information Disclosure: Implications for Privacy Paradox
}

\author{
Zahra Aivazpour \\ The University of Texas at San Antonio \\ zahra.aivazpour@utsa.edu
}

\author{
V. Srinivasan (Chino) Rao \\ The University of Texas at San Antonio \\ chino.rao@utsa.edu
}

\begin{abstract}
Privacy paradox refers to the inconsistency that sometimes exists between individuals' expressed privacy concern and the willingness to divulge personal information. Several arguments have been proposed to explain the inconsistency. One set of arguments centers around the effects of individual differences in personality characteristics, e.g., the Big Five. In the current article, we examine the role of a personality characteristic, impulsivity, in explaining the relationship between privacy concern and information disclosure. We report the results of a survey-based study that consisted of two hundred and forty-two (242) usable responses from subjects recruited on Amazon Mechanical Turk. The results show that one of the three dimensions of impulsivity, motor impulsivity, directly influences the extent of information disclosure, and, also moderates the relationship between privacy concern and information disclosure. Furthermore, our study shows impulsivity explains more variance in information disclosure than explained by the Big Five factors only.
\end{abstract}

\section{Introduction}

A topic of interest to researchers in the area of information security is the understanding of factors that influence risky cybersecurity behaviors. One risky behavior is the tendency for individuals to reveal confidential personal information [37], usually referred to as information self-disclosure, or, information disclosure. Such revelation is sometimes reflexive and spontaneous without adequate consideration of the consequences [1]. Published studies show that users have concerns about disclosing their information in digital environments, e.g., when creating personal profiles in mobile applications and/or social networks [10, 24, 45]. Some studies report that information disclosure behavior is correlated to privacy concerns of individuals [e.g., 55]. However other investigations indicate that individuals will disclose their information despite their privacy concerns [26, 35]. This disjoint between the privacy concern of individuals and their willingness to disclose confidential personal information is referred to as privacy paradox [30]. Kokolakis [30] suggests that "heuristics and biases" are the source of irrational decision making that result in privacy paradox. Other studies identify unconscious decision making [3] and bounded rationality [1] as factors that might cause information disclosure despite privacy concern. Many theories have investigated the privacy paradox phenomenon to offer explanations [30]. However, few studies have examined the role of personality characteristics on information disclosure behavior. The personality characteristics that have been studied so far include: Big Five personality traits [e.g., 16], general willingness to self-disclose [45]. We build on the idea that individual characteristics specific to a phenomenon of interest are better explanatory factors of behaviors than general personality characteristics such as the Big Five, as argued by Egelman and Peer [21]. In particular, we examine the effect of impulsivity on information disclosure.

The personality characteristic impulsivity has been shown to influence risky security related behaviors [25]. Information disclosure in the wrong context can be argued to be an example of risky security related behavior. This motivates our current examination of the role of the personality characteristic, impulsivity, in privacy paradox.

An impulse refers to the 'the urge to act spontaneously without reflecting on an action and its consequences' [18, p. 2]. The characteristic impulsivity relates to the tendency of individuals to engage in spontaneous and reflexive behaviors without adequate reflection. The actions include physical actions and verbal expressions (both oral and written). Impulsivity has been studied as a personality characteristic. Mature scales are available to measure the impulsivity of individuals. The effects of impulsivity on security related behaviors have received some attention. For example, the effect of user impulsivity on user response to phishing has been studied [13]. Also, the effect of user impulsivity on 
other security-related behaviors has been examined by [25]. However, there is no study that has examined the role of impulsivity in information disclosure especially in the privacy paradox context.

In the current study, we conducted a survey to examine the role of impulsivity in information disclosure to expand the field's understanding of the forces underlying the privacy paradox. The rest of the article is structured as follows. In section 2, we discuss relevant concepts and develop the hypotheses for the study. In section 3, we elaborate on the research methods, measures, analysis and results. In section 4, we discuss the results, and, provide concluding remarks in section 5 .

\section{Conceptual development and hypotheses}

The three key constructs in the study are information disclosure, privacy concern and impulsivity. Each of these is discussed in detail in this section, and hypotheses developed.

\subsection{Privacy and information disclosure}

Literature offers a plethora of definitions of privacy which are conceptualized from different perspectives i.e. physical, social, psychological and information privacy [26]. The current study is mainly concerned with information privacy, which is defined as users' "right to keep information about themselves from being disclosed to others" [42, p. 125]. Privacy is a complex construct that encompasses issues related to who knows what about whom under what circumstances. It is generally accepted that individuals desire to have control over personal information about themselves, i.e., to be able to decide who can access/store/know/use personal information under what circumstances. For example, Belanger and Crossler [8] indicate that "Information privacy refers to the desire of individuals to control or have some influence over data about themselves" (p. 1017). In practical terms, once information about an individual is disclosed, either voluntarily or involuntarily, the individual has limited control about who accesses and uses the information. Hence, self-disclosure of personal information is an important factor in maintaining privacy.

Privacy violation occurs when others use or distribute confidential information about one or more individuals without appropriate consent. Wang, Lee and Wang [49] state that "invasion of privacy is usually interpreted as the unauthorized collection, disclosure, or other use of personal information" (p. 64). The misused information is often presumed to be the fruit of illicit activities, such as hacking. But it is equally possible that the information may have been obtained through legal and ethical means. Individuals disclose information about self in situations where such disclosure is mandated, or, when such disclosure is necessary in obtaining services. An example of mandated disclosure would be the need to provide social security number and income related information when filing income tax returns in the United States. An example of information disclosure to obtain services would be disclosure of health-related information when seeking healthcare. Sometimes, individuals may volunteer information that is neither mandated nor necessary for acquiring services. For instance, one may divulge demographic information when purchasing products online, when such information is not necessary. Users may volunteer information without being prompted, or, provide information in response to queries or prompts. User willingness to voluntarily share personal information depends on the context [30]. Understanding information selfdisclosure behavior is important, when information disclosure is neither mandated nor necessary to receive services.

Most published studies on the topic examine information disclosure in the context of internet shopping and other online interactions [44]. With increased awareness of the potential for misuse or misappropriation of personal data by online commercial organizations, users have become wary of requests for information, and less willing to share information. Variations in unwillingness to disclose information have been attributed to privacy concerns, among other factors [55]. We discuss privacy concern in greater depth in the section 2.2.

Voluntary information disclosure can be influenced by factors, such as monetary incentives, institutional assurances, and trust. In general, consumers were more willing to provide demographic and lifestyle information than financial information (annual income) to marketers [39]. But the actual value placed on financial information appears to be quite low. In one study, subjects were willing to provide the annual income information if they were given a $€ 1$ discount on a product that they were buying [9]. In contrast, in a different study, subjects demanded about $\$ 57$ for 
information on age, and $\$ 75$ for information on weight [28]. The values placed on information do not form a coherent pattern. Nonetheless, the studies collectively indicate that there is an implicit value on personal information, and people will surrender information for a relatively low price, despite expressed privacy concerns. Institutional assurances have been demonstrated to reduce privacy concern [54] through a reduction in privacy risk perceived, and, through a sense of greater control over privacy. By implication, it can be argued that the reduction in privacy concern will lead to an increase in information disclosure. Trust is also argued to increase information disclosure [35] for example in healthcare and online shopping $[14,15]$.

\subsection{Privacy concern}

Literature appears to lack an explicit definition of the term privacy concern [37]. The term privacy has been defined, and the definition of privacy concern appears to be inferred as individual's anxiety that his/her privacy may be violated in a given context. Measures of privacy concern focus on the different ways in which privacy could be violated. Wang et al. [49] listed six ways: improper access, improper collection, improper use, improper transfer, unwanted solicitation, and improper storage. In contrast, global information privacy concern (GIPC) reflects overall concern, without addressing the dimensions of the concerns. The concern for information privacy (CFIP) reflects four dimensions of privacy concerns: collection, unauthorized secondary use, improper access, and errors [43]. Subsequently, Malhotra et al [33] developed a scale for the internet users information privacy concerns (IUIPC), which encompasses three dimensions: collection, control and awareness.

The antecedents of privacy concerns are not central to the current research. The interested reader is referred to [52] for additional sources of information on that topic.

The effects of privacy concern that are of interest are behavioral intentions and behaviors. The behavior may be information disclosure, or, an activity that requires information disclosure, such as internet purchases [52]. It has been argued that "privacy concerns ... may lead to customers being unwilling to disclose additional personal information." [19, p. 105]. Malhotra et al [33] showed that privacy concerns explained a lot of the variance in behavioral intentions.
In another study, researchers showed that privacy concern had a significant effect on online purchase intention [20]. Privacy concerns further lead to privacy protective responses, such as refusal to divulge information [37], and engaging in e-commerce [37]. Turow et al. [46] and Young and Quan-Haase [56] report a negative correlation between internet privacy concerns and information revelation. Based on these studies, we hypothesize:

Hypothesis 1: Privacy concern negatively affects information disclosure.

However, the effect of privacy concern on information disclosure intent and behavior is not consistent across studies. The term privacy paradox is used to refer to the disclosure of private information, despite privacy concern [2]. Sometimes, it is also referred to as the gap between privacy attitude and privacy behavior (or between users' privacy intention and their privacy behavior). The paradox is clearly illustrated by Williams et al (2016), who cite research illustrating diverse evidence for privacy concern and information disclosure. They cite the following evidence for the existence of privacy concern: (a) $92 \%$ of subjects worried about their privacy online according to TRUSTe, 2015; (b) $86 \%$ of subjects cleared cookies and encrypted email in an attempt to stay private online [41]; (c) $91 \%$ did not feel that consumer discounts were a fair trade for data collection [46]; and so on. Then, they cite evidence of low valuation of personal information disclosure and failure to protect online information in other studies. Study participants were willing to surrender browser history for $€ 7$ [14], and income information for $€ 1$ discount on products [9]. In contrast to results reported in [41], a 2016 survey showed that less than $20 \%$ took measures to protect online privacy measures such as using plug-ins. [12]

A variety of explanations have been offered to explain the privacy paradox. One proposed reason for privacy paradox is that that users do not always follow a rational decision making process in disclosure of their private information [11], i.e., user's privacy trade-offs are not based on a rational evaluation of the available choices but are rather based on heuristics [1]. In an e-commerce context, monetary incentives [9,14], trust in entity requesting information [48] and the type of information requested, e.g., demographic vs. financial [39] influence the extent of information disclosure. In a social networking context, the need for popularity [17] and perceived social relevance [30] 
also influence information disclosure. Lastly, the role of two personality characteristics -- Big Five personality traits [e.g., 16] and general willingness to self-disclose [45] - on information disclosure have been studied. Our interest is in understanding the role of impulsivity. The concept of impulsivity is discussed next.

\subsection{Impulsivity}

Impulsivity (also referred to as impulsiveness) is defined as "a personality trait that reflects an urge to act spontaneously, without thinking or planning ahead for the consequences of your actions" [18, p. 2]. It is a component of one or more of the dimensions of major models of personality. For an in depth discussion of the relationship between impulsivity and personality models, the reader is referred to Whiteside and Lynam [51]. The numerous theories of impulsivity and the corresponding scales for measuring impulsivity are also discussed by Whiteside and Lynam [51]. Amongst these, the one proposed by Barratt and colleagues [7] incorporates information from the medical, psychological, behavioral and social models to develop an approach to understanding impulsivity. Barratt and associates identified three components of impulsivity: attentional impulsivity, motor impulsivity and non-planning impulsivity [36]. Attentional impulsivity refers to cognitive instability and the inability to focus on tasks at hand; motor impulsivity refers to the tendency to engage in actions on the spur of the moment; and, non-planning impulsivity refers to the inability to plan complex mental tasks. The Barratt Impulsiveness Scale (BIS) is a 30-item scale [36]. The abbreviated Barratt Impulsiveness Scale (ABIS) has only 13 items has been shown to be a reliable substitute for the full form BIS [18]. Coutlee et al [18] caution that the ABIS scales are "best considered measures of separate but correlated components of impulsiveness" (p. 12). In particular, they emphasize that "ignoring the multidimensional nature of the ABIS or BIS-11 items undermines the validity of inferences made using those items" (p.12).

Impulsivity is a common diagnostic criterion for several mental disorders and forms the basis of theories explaining risky behaviors in the mental health context, such as substance abuse [52], crime [34] and gambling [47]. The role of impulsivity in non-mental health context, such as risky cyber security related behavior, has received limited attention. Some studies have adopted a narrow focus, i.e., they examine the effect on just one or a few variables. For example, it has been shown that more impulsive people are more likely to judge links as safe in fraudulent emails [13]. In another example, in the mobile computing environment, impulsive people tended to make less considered security-sensitive decisions, e.g., when working on-the-go, they processed fewer features before making a decision [29]. In contrast to the focus on single variables, Hadlington adopted a broader focus and examined the correlation of impulsivity to a range of cyber security related behaviors [25]. Hadlington's study showed that all three dimensions of impulsivity (attentional, motor and non-planning) were significant predictors of risky cyber security behaviors. Their findings have been replicated, for the most part, by Aivazpour and Rao [4].

Attentional impulsivity refers to cognitive instability and the inability to focus on tasks at hand. The resulting lack of attention leads to spontaneous and ill-considered decisions, especially when the task is complex. Presumably, lack of attention is a precursor to rapid, unplanned reactions to internal or external stimuli. Individuals who show attentional impulsivity are unable to delay gratification. Uses and gratification of social media such as entertainment, communication, and affect encourage users to disclose their personal information online [40]. Other researchers have shown that attentional impulsivity positively affects risky cyber security behavior [4, 25] Four of the behaviors in Hadlington's list relate to information disclosure (e.g., Sending personal information to strangers over the Internet). Based on the evidence of the effect of impulsivity on risky cyber security behavior, and the inclusion of information disclosure behaviors as components of risky cyber security behavior, we hypothesize:

Hypothesis 2: Lack of attention impulsivity will positively affect information disclosure.

Motor impulsiveness involves acting without thinking and refers to the tendency to engage in actions on the spur of the moment. Time pressure has been discussed as a precipitating factor of motor impulsivity. Motor impulsiveness is also correlated with the action/inhibition task performance in the presence of a stimuli [5] and risky cyber security behavior [4, 25]. Based on this, we hypothesize:

Hypothesis 3: Motor impulsivity will positively affect information disclosure. 
Non-planning impulsivity refers to the inability to plan complex mental tasks. Non-planning impulsiveness involves a lack of forethought, selfcontrol and cognitive complexity. The ability to make advantageous choices depends greatly on the capacity to plan ahead and/or to inhibit an ill thought-out response. According to construal distance theory, high-level aspects of the same behavior are valued more in distant-future decisions, while low-level aspects are valued more in near-future decisions. Hallam and Zanella [26] argue that privacy risk is high-level since it is perceived as hypothetical and distant. Individuals who plan ahead, are expected to be more concerned about their future privacy issues, and consequently disclose less information, compared to those who show signs of non-planning impulsiveness. Based on this, we hypothesize:

Hypothesis 4: Non-planning impulsivity will positively affect information disclosure.

Another interest of ours is in examining if impulsivity has a further role in explaining the privacy paradox. Contradictory results regarding the significance of privacy concern as an antecedent of information disclosure can be attributed to the impact of the moderating variables, an idea that has been minimally examined. For example, Bansal and Zahedi [6] have shown that trust moderates the relationship between privacy concerns and information disclosure. Similarly, it can be argued that other factors including dimensions of impulsivity may also be moderators. Individuals with low impulsivity will behave in a thoughtful and reflective way allowing their privacy concern to guide their information disclosure behaviors. In contrast, individuals with high impulsivity will act in a spontaneous manner without adequate reflection, overcoming the influence exerted by privacy concern on information disclosure. In effect, impulsivity will moderate the relationship between privacy concern and information disclosure. Based on this, we hypothesize:

Hypothesis 5: Attentional impulsivity will moderate the relationship between privacy concern and information disclosure.

Hypothesis 6: Motor impulsivity will moderate the relationship between privacy concern and information disclosure.

Hypothesis 7: Non-planning impulsivity will moderate the relationship between privacy concern and information disclosure.

\section{Research methods and analysis}

\subsection{Measurements and data collection}

The data was collected in the United States via a survey on Amazon Mechanical Turk. The survey did not specify a particular context, but instead captured responses in a general context. In addition to the items for personality traits, privacy concern and information disclosure, trap questions were included in the survey to remove random responses. Two hundred and sixtyeight (268) responses were collected. We dropped 18 incomplete responses, because less than $50 \%$ of the survey was completed. An additional 8 data points were filtered out by the trap questions. In the remaining 242 data points, 7 had missing values (total 12 missing values). Additionally, some demographic information was missing -5 for gender, 2 for age, and 5 for educational level. All missing values were imputed by the mean replacement algorithm embedded in SmartPLS. We used the original 13- item Abbreviated Barratt Information Scale (ABIS) [see 18] to measure three dimensions of impulsivity. The scale has been validated and found to be stable, although a few items had weak loadings in some replications [18]. For privacy concern, we used the scale from $\mathrm{Xu}$ et al [53], who adapted and validated the concern for information privacy (CFIP) scale from Smith et al [43]. The information disclosure scale was adapted from Hallam and Zanella [26] as follows. For example, the original wording "What kind of information do you openly share online?: My financial problems," was modified to "I openly share my financial problems online" in our study to reflect the changed context. Further, Hallam and Zanella dropped three of six items from their measure because the items had low factor loadings. We included all six items. (For items, see Table A2 in the Appendix). Demographic variables age, gender and education were added to the model as controls and were measured using categorical scales. The number of male participants is about 10 percent more than female respondents. More than half of participants are young adults. College students make up about $50 \%$ of our sample. (See Table A1 in the Appendix for more details on demographics).

The results of the exploratory factor analysis are shown in Table A2 in the Appendix. Principal axis factoring method was used for factor extraction and we rotated the items using Promax method. Based on the exploratory factor analysis (EFA) results, two of items for impulsivity ("I don't pay attention"; and "I 
plan tasks carefully") were removed due to low factor loadings. The scale for privacy concern factor as expected. All items for information disclosure had high factor loadings, and were retained.

The research model was evaluated using partial least squares (PLS). This method has been shown to be robust for small sample sizes and for non-normally distributed data. PLS provides advantages for preliminary theory building and exploratory models. Furthermore, PLS measures interactions and moderation effects more effectively compared to covariance-based structural equation modeling (CBSEM) [31].

All the measures were found to be reliable as they met the 0.7 cutoff for internal reliability (see Table 1 ). The average variance extracted (AVE) is also shown in Table 1.

\begin{tabular}{|l|c|c|c|}
\hline \multicolumn{4}{|c|}{ Table 1. Reliability } \\
\hline & $\begin{array}{c}\text { Cronbach's } \\
\text { Alpha }\end{array}$ & $\begin{array}{c}\text { Composite } \\
\text { Reliability }\end{array}$ & AVE \\
\hline ATT & 0.777 & 0.855 & 0.598 \\
\hline ID & 0.902 & 0.925 & 0.676 \\
\hline MR & 0.837 & 0.891 & 0.672 \\
\hline NP & 0.741 & 0.816 & 0.604 \\
\hline PC & 0.901 & 0.926 & 0.715 \\
\hline
\end{tabular}

ATT: attentional impulsivity, MR: motor impulsivity, NP: nonplanning impulsivity, ID: information disclosure, PC: privacy concern

The correlations between the variables are shown in Table 2. Variance inflation factors (VIF values) ranged from 1.8 to 5.2, which are in the acceptable range. The diagonal shows the square root of each Average Variance Extracted (AVE). The AVE values are greater than the corresponding correlation coefficients, thus establishing discriminant validity, based on the Fornell and Larcker criterion [24].

Table 2. Correlations and discriminant validity

\begin{tabular}{|l|c|c|c|c|c|}
\hline & ATT & ID & MR & NP & PC \\
\hline ATT & 0.773 & & & & \\
\hline ID & 0.236 & 0.822 & & & \\
\hline MR & 0.358 & 0.515 & 0.82 & & \\
\hline NP & 0.465 & 0.16 & 0.253 & 0.777 & \\
\hline PC & -0.283 & -0.241 & -0.213 & -0.135 & 0.846 \\
\hline
\end{tabular}

Cross loadings of items after dropping the two low-loading items are shown in Table A3 in the Appendix.

\subsection{Path analysis and summary of results}

The results of the path analysis are shown in Figure 1 and Table 3. They show that the negative association between privacy concern and information disclosure (self-report) was significant in the model, supporting hypothesis 1 . Motor impulsivity was associated with increased information disclosure supporting hypothesis 3 . However, neither attentional impulsivity nor non-planning impulsivity was found to significantly affect information disclosure, which leads to the rejection of hypotheses 2 and 4 .

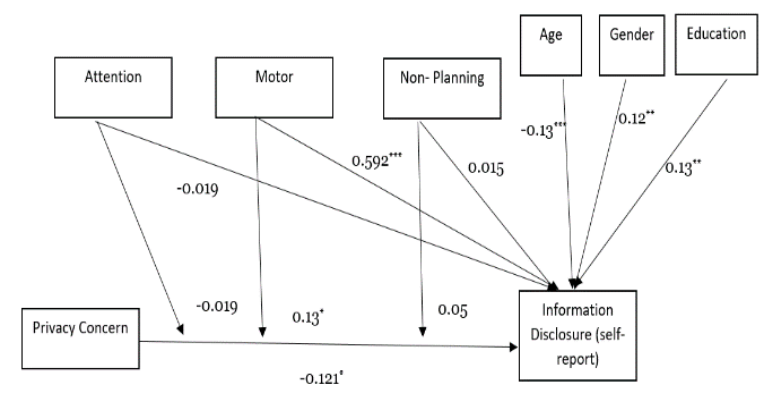

Figure 1. Path coefficients and significance

$* \mathrm{p}<0.05, * * \mathrm{p}<0.01, * * * \mathrm{p}<0.001$

\begin{tabular}{|l|c|c|c|}
\hline \multicolumn{4}{|c|}{ Table 3. Path analysis } \\
\hline \multicolumn{1}{|c|}{ Hypothesis } & Estimate & $\begin{array}{c}\mathrm{T} \\
\text { Statistics }\end{array}$ & $\begin{array}{c}\mathrm{P} \\
\text { Value }\end{array}$ \\
\hline $\mathrm{H} 1(-):$ PC $\rightarrow$ ID & $-0.121^{*}$ & 2.236 & 0.026 \\
\hline $\begin{array}{l}\mathrm{H} 2(+): \text { attention } \rightarrow \\
\text { ID }\end{array}$ & -0.019 & 0.273 & 0.785 \\
\hline $\mathrm{H} 3(+):$ motor $\rightarrow$ ID & $0.592^{* * *}$ & 10.456 & 0.000 \\
\hline $\begin{array}{l}\mathrm{H} 4(+): \text { non- } \\
\text { planning } \rightarrow \text { ID }\end{array}$ & 0.015 & 0.209 & 0.835 \\
\hline $\begin{array}{l}\text { H5(+): } \\
\text { attention*PC } \rightarrow \text { ID }\end{array}$ & -0.101 & 1.475 & 0.141 \\
\hline $\begin{array}{l}\text { H6(+):motor*PC } \rightarrow \\
\text { ID }\end{array}$ & $0.13^{*}$ & 2.169 & 0.031 \\
\hline $\begin{array}{l}\text { H7(+):non- } \\
\text { planning*PC } \rightarrow \text { ID }\end{array}$ & 0.05 & 0.894 & 0.372 \\
\hline Age & $-0.13^{* * *}$ & 3.388 & 0.000 \\
\hline Education & $0.13^{* *}$ & 2.981 & 0.002 \\
\hline Gender & $0.12^{* *}$ & 2.943 & 0.003 \\
\hline $\begin{array}{l}* p \\
\text { information disclosure; } \mathrm{R}^{2}: 0.51 ; \mathrm{R}^{2} \text { Adjusted: } 0.493\end{array}$ \\
\hline
\end{tabular}

The results also indicate that the interaction between privacy concern and motor impulsivity positively affects information disclosure, supporting hypothesis 6. However, both hypotheses 5 and 7 were rejected, since the interaction between privacy concern and attentional impulsivity, and, the interaction between privacy concern and non-planning impulsivity did not significantly influence information disclosure. 
The three demographic variables - age, education and gender -- were found to be significant. Older individuals tended to disclose less information compared to the younger individuals. Men shared more information online compared to women. Education level, was also positively associated with information disclosure.

\subsection{Big Five vs. impulsivity}

Egelman and Peer [21] have argued that personality traits closer to the phenomenon of interest provide greater explanatory power than Big Five characteristics. To test this assertion, as a post hoc analysis, we examined if impulsivity as a personality characteristic adds any significant explanation to information disclosure after accounting for Big Five personality traits, measured using Big Five scales published by Gosling, Rentfrow and Swann [23] (see Table A4 in Appendix for items). Results of discriminant validity test between the Big Five constructs and impulsivity constructs are shown in Table A5 in the Appendix.

To this end, we ran a hierarchical regression model (see Table A6 in the Appendix for details). In step 1, we only entered control variables - age, gender and education. The variance explained was $20.8 \%$. In the next step, privacy concern and Big Five personality traits were added to the model. Together, they explain 34.7 percent of variance in information disclosure, indicating that the Big Five personality factors have significant explanatory power. In step 3, in which impulsivity was added as a predictor, R-Square increased to 46.1 percent. F statistics calculated for the R-Squared change shows that the additional variance explained is statistically significant. This provides preliminary evidence that impulsivity has explanatory power over and beyond what is provided by the Big Five factors. It should be pointed out that theoretical models of personality other than the Big Five have been proposed [see 49]. The effect of other personality models on information disclosure should also be examined in future research.

\section{Discussion}

The primary goal of the study was to examine the role of impulsivity in information disclosure and privacy paradox. Motor impulsivity has been shown to influence information disclosure, and also moderate the relationship between privacy concern and information disclosure. Clearly, one component of impulsivity, i.e., motor impulsivity, contributes to the understanding of information disclosure and privacy paradox. In contrast, neither attentional impulsivity, nor non-planning enhanced understanding of information disclosure or privacy paradox. This is consistent with findings in earlier studies, in which motor impulsivity provided greater explanation than the other components of impulsivity. For instance, of the total $45 \%$ of variance in risky cyber security behaviors explained by impulsivity components, only about 5\% was explained by attentional and nonplanning impulsivities [4].

The difference in the effects of the components of impulsivity can be best explained by the nature of the information disclosure in the current study, i.e., sharing information online. The attention needed to be aware of the information being requested by an online site is likely to be minimal, and thus even subjects with high attentional impulsivity seem to be able to know whether to provide the information or not. Online information is provided using physical input devices a motor activity. Typing, clicking on check boxes, selecting radio buttons tend to be reflexive actions for most people. People high in motor impulsivity lack the inhibitory control necessary to counteract the reflexive and spontaneous nature of information input, while those low in motor impulsivity are able to make considered decisions about information disclosure. With respect to non-planning impulsivity, people seldom plan in advance on what information to divulge to online sites. So, non-planning impulsivity does not show a significant relationship to information disclosure. Overall, in the online environment, it appears that information disclosure is more associated with physical/ bodily acts (motor impulsiveness) than concentration (attentional impulsiveness) and forethought (non-planning impulsiveness).

Further, one can argue that many online applications (e.g., e-commerce purchases, playing video games, dating apps and so on) are related to sensation seeking and enjoyment, susceptible to impulsive urges. The rich and stimulating environment of these applications are likely to result in quick and spontaneous decision-making about information disclosure. Since many of the behaviors related to information disclosure in these online applications are motor activities, they are likely to be related to motor impulsivity.

Next, the study provides support for the theoretical argument that privacy concern influences information 
disclosure, since hypothesis 1 is supported. This implies that privacy paradox results from the presence of other factors that moderate the relationship. In the current study, the moderating effect of motor impulsivity on the relationship between privacy concern and information disclosure is evidence of the role of motor impulsivity on privacy paradox. At higher levels of motor impulsivity, the relationship between privacy concern and information disclosure is weakened or eliminated; at lower levels of motor impulsivity, the relationship is unaffected.

A secondary objective of the study was to examine the Egelman-Peer assertion [21] that personality characteristics closer to a concept of interest will be better predictors than the Big Five factors. Our study shows that impulsivity components explain variance in information disclosure over and beyond what the Big Five factors do, thus providing initial support the Egelman-Peer assertion.

Another finding of interest relates to the conceptualization of impulsivity. It has been theorized that the three dimensions of impulsivity are separate but connected components [18]. The results of the current study provide support for this conceptualization. Motor impulsivity plays a highly significant role, while attentional impulsivity and nonplanning impulsivity are not significant.

\section{Conclusion and future research}

The current study is the first to investigate the role of impulsivity as a personality characteristic in the information disclosure context. The results are promising and contribute to the body of knowledge by providing insights for scholars. In terms of practice, it points to the need for training to help impulsive individuals make more considered decisions. Technological approaches could also be tried to retard impulsivity. For instance, users may be asked to confirm that they wish to share the personal information, which will give them pause, a moment to reflect on whether they wish to disclose information. Alternately, the link could be greyed out and inactive for a few seconds thwarting an impulsive response (this suggestion from one of the reviewers is gratefully acknowledged). The main limitation of this study is that information disclosure behavior is a self-report measure. Such measures are subject to recall errors. Direct observation or measure of information disclosure behavior is needed to confirm the results.
The technical trend in input devices is towards voice-based input. Siri and Alexa for instance are advanced voice-based devices that are used extensively. The impulsivity component that influences information disclosure in the voice mode would be an interesting area of research. Another avenue of future research would be to investigate the pathways by which different components of impulsivity influence behavior. Overall, we have provided preliminary evidence that impulsivity has a significant role in helping us understand information disclosure behavior and the privacy paradox phenomenon. The robustness of the role has to be established by using diverse research methods and measures of information disclosure.

Acknowledgements: We thank the reviewers, and, the mini-track and track chairs for their constructive suggestions. We also thank Prof. Daniel Sass for assistance with statistics. Residual errors and shortcomings remain the sole responsibility of the authors.

\section{References}

[1] Acquisti, Alessandro, and Jens Grossklags. What can behavioral economics teach us about privacy. Digital Privacy: Theory, Technologies and Practices 18 (2007): 363-377.

[2] Acquisti, Alessandro, Laura Brandimarte, and George Loewenstein. Privacy and human behavior in the age of information. Science 347.6221 (2015): 509-514.

[3] Aivazpour, Zahra, Rohit Valecha, and Raghav H. Rao. Unpacking Privacy Paradox: A Dual Process Theory Approach. Proceedings of the AMCIS, Boston (2017).

[4] Aivazpour, Zahra, and V. Srinivasan (Chino) Rao. Impulsivity and Risky Cybersecurity Behaviors: A Replication. Proceedings of the AMCIS, New Orleans, (2018).

[5] Arce, Estíbaliz, and Carmen Santisteban. Impulsivity: a review. Psicothema 18.2 (2006).

[6] Bansal, Gaurav, and Fatemeh Zahedi. The moderating influence of privacy concern on the efficacy of privacy assurance mechanisms for building trust: A multiple-context investigation. ICIS 2008 Proceedings (2008): 7.

[7] Barratt, E. S. Impulsivity: Integrating cognitive, behavioral, biological and environmental data. In W. McCowan, J. Johnson, and M. Shure (Eds.), The Impulsive client: Theory, Research, and Treatment (1993): 39-56. Washington, DC: American Psychological Association. 
[8] Bélanger, France, and Robert E. Crossler. Privacy in the digital age: a review of information privacy research in information systems. MIS Quarterly 35.4 (2011): 10171042.

[9] Beresford, Alastair R., Dorothea Kübler, and Sören Preibusch. Unwillingness to pay for privacy: A field experiment. Economics Letters 117.1 (2012): 25-27.

[10] Boyles, Jan Lauren, Aaron Smith, and Mary Madden. Privacy and data management on mobile devices. Pew Internet and American Life Project 4 (2012). $<$ http://pewinternet.org/Reports/2012/MobilePrivacy.aspx >; 2012 [accessed 10.02.15].

[11] Brandimarte, Laura, Alessandro Acquisti, and George Loewenstein. Misplaced confidences: Privacy and the control paradox. Social Psychological and Personality Science 4.3 (2013): 340-347.

[12] BusinessWire, Study: Consumers remain carelessly indifferent to online security and privacy. < https://www.businesswire.com/news/home/2016021800514 2/en/Study-U.S.-Consumers-Remain-Carelessly$\underline{\text { Indifferent-Online }>2016 \text {. [accessed 09.02.2018] }}$

[13] Butavicius, Marcus, Kathryn Parsons, Malcolm Pattinson, and Agata McCormac. Breaching the human firewall: Social engineering in phishing and spear-phishing emails. arXiv preprint arXiv:1606.00887 (2016).

[14] Carlos Roca, Juan, Juan José García, and Juan José de la Vega. The importance of perceived trust, security and privacy in online trading systems. Information Management and Computer Security 17.2 (2009): 96-113.

[15] Chakraborty, R., Lee, J., Bagchi-Sen, S., Upadhyaya, S., and Rao, H. R. Online shopping intention in the context of data breach in online retail stores: An examination of older and younger adults. Decision Support Systems, 83, (2016): 47-56.

[16] Chen, Jengchung Victor, Andree E. Widjaja, and David C. Yen. Need for affiliation, need for popularity, selfesteem, and the moderating effect of Big Five personality traits affecting individuals' self-disclosure on Facebook. International Journal of Human-Computer Interaction 31.11 (2015): 815-831.

[17] Christofides, Emily, Amy Muise, and Serge Desmarais. Hey mom, what's on your Facebook? Comparing Facebook disclosure and privacy in adolescents and adults. Social Psychological and Personality Science 3.1 (2012): 48-54.

[18] Coutlee, Christopher G., Cary S. Politzer, Rick H. Hoyle, and Scott A. Huettel. An Abbreviated Impulsiveness Scale constructed through confirmatory factor analysis of the Barratt Impulsiveness Scale Version 11. Archives of Scientific Psychology, (2014). 2(1), 1.
[19] Culnan, Mary J., and Pamela K. Armstrong. Information privacy concerns, procedural fairness, and impersonal trust: An empirical investigation. Organization Science 10.1 (1999): 104-115.

[20] Eastlick, Mary Ann, Sherry L. Lotz, and Patricia Warrington. Understanding online B-to-C relationships: An integrated model of privacy concerns, trust, and commitment. Journal of Business Research 59.8 (2006): 877-886.

[21] Egelman, S., and Peer, E.. Predicting Privacy and Security Attitudes, Computers and Society: The Newletter of ACM SIGCAS, (45:1), (2015): 22-28.

[22] Fornell, Claes, and David F. Larcker. Structural equation models with unobservable variables and measurement error: Algebra and statistics. Journal of Marketing Research (1981): 382-388.

[23] Gosling, Samuel D., Peter J. Rentfrow, and William B. Swann Jr. A very brief measure of the Big-Five personality domains. Journal of Research in personality 37.6 (2003): 504-528.

[24] Gross, Ralph, and Alessandro Acquisti. Information revelation and privacy in online social networks. Proceedings of the 2005 ACM workshop on Privacy in the electronic society. ACM, (2005).

[25] Hadlington, Lee. Human factors in cybersecurity; examining the link between Internet addiction, impulsivity, attitudes towards cybersecurity, and risky cybersecurity behaviours. Heliyon 3.7 (2017): e00346.

[26] Hallam, Cory, and Gianluca Zanella. Online selfdisclosure: The privacy paradox explained as a temporally discounted balance between concerns and rewards. Computers in Human Behavior 68 (2017): 217-227.

[27] Hann, Il-Horn, Kai-Lung Hui, Sang-Yong Tom Lee, and Ivan PL Png. Overcoming online information privacy concerns: An information-processing theory approach. Journal of Management Information Systems 24, no. 2 (2007): 13-42.

[28] Huberman, Bernardo A., Eytan Adar, and Leslie R. Fine. Valuating privacy. IEEE Security and Privacy 3.5 (2005): 22-25.

[29] Jeske, Debora, and Kenneth S. Shultz. Using social media content for screening in recruitment and selection: pros and cons. Work, Employment and Society 30.3 (2016): 535-546.

[30] Kokolakis, Spyros. Privacy attitudes and privacy behaviour: A review of current research on the privacy paradox phenomenon. Computers and Security 64 (2017): 122-134. 
[31] Lowry, Paul Benjamin, and James Gaskin. Partial least squares (PLS) structural equation modeling (SEM) for building and testing behavioral causal theory: When to choose it and how to use it. IEEE Transactions on Professional Communication 57.2 (2014): 123-146.

[33] Malhotra, Naresh K., Sung S. Kim, and James Agarwal. Internet users' information privacy concerns (IUIPC): The construct, the scale, and a causal model. Information Systems Research 15.4 (2004): 336-355.

[34] Moffitt, Terrie E. Adolescence-limited and life-coursepersistent antisocial behavior: a developmental taxonomy. Psychological Review 100.4 (1993): 674.

[35] Norberg, Patricia A., Daniel R. Horne, and David A. Horne. The privacy paradox: Personal information disclosure intentions versus behaviors. Journal of Consumer Affairs 41.1 (2007): 100-126.

[36] Patton, Jim H., Matthew S. Stanford, and Ernest S. Barratt. Factor structure of the Barratt impulsiveness scale. Journal of Clinical Psychology 51.6 (1995): 768-774.

[37] Pavlou, Paul A. State of the information privacy literature: Where are we now and where should we go? MIS Quarterly (2011): 977-988.

[38] Podsakoff, P. M., MacKenzie, S. B., Lee, J., and Podsakoff, N. P. Common method biases in behavioral research: A critical review of the literature and recommended remedies. Journal of Applied Psychology, 88(5) (2003): 879-903. doi:http://dx.doi.org/10.1037/00219010.88.5.879

[39] Phelps, Joseph, Glen Nowak, and Elizabeth Ferrell. Privacy concerns and consumer willingness to provide personal information. Journal of Public Policy and Marketing 19.1 (2000): 27-41.

[40] Quinn, Kelly. Why we share: A uses and gratifications approach to privacy regulation in social media use. Journal of Broadcasting and Electronic Media 60.1 (2016): 61-86.

[41] Rainie, L., Kiesler, S., Kang, R., Madden, M., Duggan, M., Brown, S., and Dabbish, L. Anonymity, privacy, and security online. Pew Research Center, 5 (2013).

[42] Rognehaugh, Richard. The health information technology dictionary. Aspen Publishers, (1999).

[43] Smith, H. Jeff, Sandra J. Milberg, and Sandra J. Burke. Information privacy: measuring individuals' concerns about organizational practices. MIS Quarterly (1996): 167-196.

[44] Son, Jai-Yeol, and Sung S. Kim. Internet users' information privacy-protective responses: a taxonomy and a nomological model. MIS Quarterly (2008): 503-529.

[45] Taddicken, Monika. The 'privacy paradox' in the social web: The impact of privacy concerns, individual characteristics, and the perceived social relevance on different forms of self-disclosure. Journal of ComputerMediated Communication 19.2 (2014): 248-273.

[46] Turow, Joseph, Michael Hennessy, and Nora A. Draper. The tradeoff fallacy: How marketers are misrepresenting American consumers and opening them up to exploitation. (2015).

[47] van Holst, Ruth J., et al. Interactions between affective and cognitive processing systems in problematic gamblers: a functional connectivity study. PLoS One 7.11 (2012): e49923.

[48] Wakefield, Robin. The influence of user affect in online information disclosure. The Journal of Strategic Information Systems 22.2 (2013): 157-174.

[49] Wang, Huaiqing, Matthew KO Lee, and Chen Wang. Consumer privacy concerns about Internet marketing. Communications of the ACM 41.3 (1998): 63-70.

[50] Wheeless, Lawrence R., and James Grotz. Conceptualization and measurement of reported selfdisclosure. Human Communication Research 2.4 (1976): 338-346.

[51] Whiteside, Stephen P., and Donald R. Lynam. The five factor model and impulsivity: Using a structural model of personality to understand impulsivity. Personality and Individual Differences 30.4 (2001): 669-689.

[52] Wills, Thomas Ashby, Donato Vaccaro, and Grace McNamara. Novelty seeking, risk taking, and related constructs as predictors of adolescent substance use: an application of Cloninger's theory. Journal of Substance Abuse 6.1 (1994): 1-20.

[53] Xu, Heng, Tamara Dinev, H. Jeff Smith, and Paul Hart. Examining the formation of individual's privacy concerns: Toward an integrative view. ICIS 2008 Proceedings (2008): 6.

[54] Xu, Heng, Tamara Dinev, Jeff Smith, and Paul Hart. Information privacy concerns: Linking individual perceptions with institutional privacy assurances. Journal of the Association for Information Systems 12, no. 12 (2011): 798.

[55] Young, Alyson L., and Anabel Quan-Haase. Information revelation and internet privacy concerns on social network sites: a case study of facebook. Proceedings of the fourth International Conference on Communities and Technologies. ACM, 2009.

[56] Young, Alyson Leigh, and Anabel Quan-Haase. Privacy protection strategies on Facebook: The Internet privacy paradox revisited. Information, Communication and Society 16.4 (2013): 479-500. 


\section{Appendix A}

Appendix A includes the following tables.

Table A1. Demographics

Table A2. Exploratory Factor Analysis

Table A3. $\quad$ Cross Loadings of Items with Two Items Dropped

Table A4. Big Five Items

Table A5. Discriminant Validity Test Between Big Five and Impulsivity Constructs

Table A6. Hierarchical Regression Results

\begin{tabular}{|c|c|c|}
\hline \multicolumn{3}{|c|}{ Table A1. Demographics } \\
\hline Demographics & Frequency & Percent \\
\hline \multicolumn{3}{|l|}{ Gender } \\
\hline female & 107 & 44.2 \\
\hline male & 130 & 53.7 \\
\hline \multicolumn{3}{|l|}{ Age } \\
\hline$<19$ & 2 & 0.8 \\
\hline $20-25$ & 38 & 15.7 \\
\hline $26-30$ & 72 & 29.8 \\
\hline $31-35$ & 32 & 13.2 \\
\hline $36-40$ & 31 & 12.8 \\
\hline $40>$ & 63 & 26 \\
\hline \multicolumn{3}{|l|}{ Education } \\
\hline Less than high school & 2 & 0.8 \\
\hline High school & 46 & 19 \\
\hline College & 123 & 50.8 \\
\hline Graduate & 66 & 27.3 \\
\hline
\end{tabular}

As the respondents could skip demographic questions, the demographic information of a few respondents are missing. 


\begin{tabular}{|c|c|c|c|c|c|}
\hline \multicolumn{6}{|c|}{ Table A2. Exploratory Factor analysis } \\
\hline Items & Attention & Motor & $\begin{array}{c}\text { Non } \\
\text { planning }\end{array}$ & $\begin{array}{l}\text { Privacy } \\
\text { concern }\end{array}$ & $\begin{array}{c}\text { Information } \\
\text { disclosure }\end{array}$ \\
\hline I don't pay attention. & 0.389 & 0.291 & & & \\
\hline I am self-controlled. & 0.575 & & & & \\
\hline I concentrate easily. & 0.652 & & & & \\
\hline I am a careful thinker. & 0.666 & & & & \\
\hline I am a steady thinker. & 0.809 & & & & \\
\hline I do things without thinking. & & 0.678 & & & \\
\hline I say things without thinking. & & 0.711 & & & \\
\hline I act "on impulse". & & 0.818 & & & \\
\hline I act on the spur of the moment. & & 0.825 & & & \\
\hline I plan tasks carefully. & & 0.366 & 0.249 & & \\
\hline I plan trips well ahead of time. & & & 0.592 & & \\
\hline I plan for job security. & & & 0.689 & & \\
\hline I am future oriented. & & & 0.783 & & \\
\hline $\begin{array}{l}\text { It bothers me when these websites ask me for this } \\
\text { much personal information. }\end{array}$ & & & & 0.819 & \\
\hline $\begin{array}{l}\text { I am concerned that these websites are collecting too } \\
\text { much personal information about me. }\end{array}$ & & & & 0.824 & \\
\hline $\begin{array}{l}\text { I am concerned that unauthorized people may access } \\
\text { my personal information. }\end{array}$ & & & & 0.818 & \\
\hline $\begin{array}{l}\text { I am concerned that these websites may keep my } \\
\text { personal information in a non-accurate manner. }\end{array}$ & & & & 0.828 & \\
\hline $\begin{array}{l}\text { I am concerned about submitting information to } \\
\text { websites. }\end{array}$ & & & & 0.814 & \\
\hline $\begin{array}{l}\text { I openly share my personal information like age, home } \\
\text { address, favorite restaurants online. }\end{array}$ & & & & & 0.767 \\
\hline $\begin{array}{l}\text { I openly share my personal thoughts, feelings and } \\
\text { experiences online. }\end{array}$ & & & & & 0.609 \\
\hline I openly share my financial problems online. & & & & & 0.886 \\
\hline $\begin{array}{l}\text { From my online profile, it would be easy to } \\
\text { understand what type of person I am. }\end{array}$ & & & & & 0.655 \\
\hline I openly share my medical history online. & & & & & 0.882 \\
\hline I openly share my health information online. & & & & & 0.874 \\
\hline
\end{tabular}




\begin{tabular}{|l|c|c|c|c|c|}
\hline \multicolumn{7}{|l|}{ Table A3. Cross loadings of Items with Two Items Dropped } \\
\hline & ID & ATT & MR & NP & PC \\
\hline ID1 & $\mathbf{0 . 8 2 7}$ & 0.187 & 0.446 & 0.142 & -0.233 \\
\hline ID2 & $\mathbf{0 . 6 7}$ & 0.164 & 0.36 & 0.057 & -0.088 \\
\hline ID3 & $\mathbf{0 . 8 9 9}$ & 0.211 & 0.456 & 0.142 & -0.257 \\
\hline ID4 & $\mathbf{0 . 7 0 5}$ & 0.143 & 0.344 & 0.069 & -0.092 \\
\hline ID5 & $\mathbf{0 . 9 0 3}$ & 0.197 & 0.456 & 0.155 & -0.202 \\
\hline ID6 & $\mathbf{0 . 8 9 7}$ & 0.246 & 0.434 & 0.178 & -0.251 \\
\hline ATT1 & 0.137 & $\mathbf{0 . 6 9 3}$ & 0.208 & 0.364 & -0.137 \\
\hline ATT2 & 0.175 & $\mathbf{0 . 7 6 6}$ & 0.298 & 0.371 & -0.254 \\
\hline ATT3 & 0.179 & $\mathbf{0 . 7 7 1}$ & 0.294 & 0.416 & -0.204 \\
\hline ATT4 & 0.224 & $\mathbf{0 . 8 5 3}$ & 0.296 & 0.313 & -0.259 \\
\hline MR1 & 0.415 & 0.283 & $\mathbf{0 . 8 0 1}$ & 0.176 & -0.173 \\
\hline MR2 & 0.426 & 0.316 & $\mathbf{0 . 8 2 1}$ & 0.221 & -0.189 \\
\hline MR3 & 0.411 & 0.338 & $\mathbf{0 . 8 3 3}$ & 0.215 & -0.133 \\
\hline MR4 & 0.457 & 0.228 & $\mathbf{0 . 8 2 4}$ & 0.22 & -0.206 \\
\hline NP1 & 0.161 & 0.394 & 0.214 & $\mathbf{0 . 9 0 8}$ & -0.128 \\
\hline NP2 & 0.009 & 0.416 & 0.206 & $\mathbf{0 . 5 7 9}$ & -0.153 \\
\hline NP3 & 0.112 & 0.403 & 0.222 & $\mathbf{0 . 8 0 7}$ & -0.096 \\
\hline PC1 & -0.237 & -0.246 & -0.178 & -0.128 & $\mathbf{0 . 8 5 8}$ \\
\hline PC2 & -0.218 & -0.279 & -0.215 & -0.093 & $\mathbf{0 . 8 5 7}$ \\
\hline PC3 & -0.175 & -0.201 & -0.166 & -0.136 & $\mathbf{0 . 8 3 1}$ \\
\hline PC4 & -0.192 & -0.244 & -0.16 & -0.061 & $\mathbf{0 . 8 4 5}$ \\
\hline PC5 & -0.189 & -0.218 & -0.178 & -0.157 & $\mathbf{0 . 8 3 9}$ \\
\hline
\end{tabular}

Dropped Items: (1) I don't pay attention (2) I plan tasks carefully.

ID: information disclosure; ATT: attention impulsivity; MR: Motor impulsivity; NP: non-planning impulsivity; PC: privacy concern

\begin{tabular}{|c|c|c|}
\hline \multicolumn{3}{|c|}{ Table A4. Big Five Items } \\
\hline Constructs & Items & Source \\
\hline Big Five & 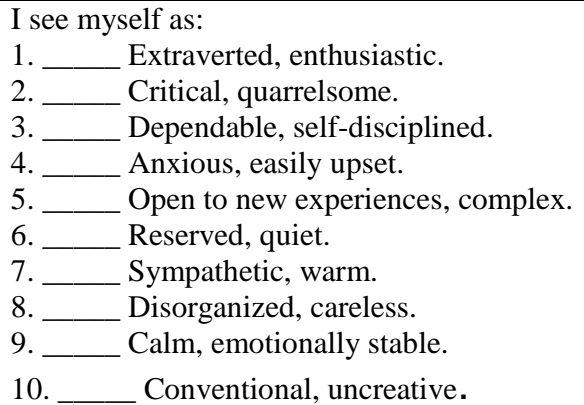 & $\begin{array}{l}\text { Gosling, Samuel D., Peter J. Rentfrow, and } \\
\text { William B. Swann Jr. "A very brief measure of } \\
\text { the Big-Five personality domains." Journal of } \\
\text { Research in personality } 37.6 \text { (2003): 504-528. }\end{array}$ \\
\hline
\end{tabular}




\begin{tabular}{|c|c|c|c|c|c|c|c|c|c|c|}
\hline \multicolumn{11}{|c|}{ Table A5 - Discriminant Validity Test Between Big Five and Impulsivity Constructs } \\
\hline & ID & $\mathrm{PC}$ & agr & attention & cons & neu & extr & motor & $\begin{array}{c}\text { non } \\
\text { planning }\end{array}$ & open \\
\hline ID & 0.822 & & & & & & & & & \\
\hline $\mathrm{PC}$ & -0.237 & 0.849 & & & & & & & & \\
\hline agr & -0.431 & 0.086 & 0.727 & & & & & & & \\
\hline attention & 0.293 & -0.293 & -0.347 & 0.707 & & & & & & \\
\hline cons & -0.444 & 0.253 & 0.464 & -0.545 & 0.808 & & & & & \\
\hline neu & -0.282 & -0.023 & 0.482 & -0.435 & 0.45 & 0.805 & & & & \\
\hline extr & 0.445 & -0.009 & -0.082 & -0.078 & -0.055 & 0.164 & 0.702 & & & \\
\hline motor & 0.61 & -0.222 & -0.561 & 0.463 & -0.522 & -0.418 & 0.159 & 0.823 & & \\
\hline non planning & 0.227 & -0.243 & -0.249 & 0.587 & -0.483 & -0.25 & -0.130 & 0.392 & 0.729 & \\
\hline open & -0.309 & 0.000 & 0.220 & -0.098 & 0.197 & 0.278 & -0.121 & -0.198 & -0.014 & 0.688 \\
\hline
\end{tabular}

ID: information disclosure; PC: privacy concern; agr: agreeableness; attention: attention impulsivity; cons: conscientiousness; neu: neuroticism; extr: extraversion; motor: motor impulsivity; non-planning: non-planning impulsivity; open: openness

Values along the diagonal show AVE values. Values in other cells show cross correlations between variables.

\begin{tabular}{|l|c|c|c|c|c|}
\hline \multicolumn{7}{|c|}{ Table A6. Hierarchical Regression } \\
\hline Model & $\mathrm{R}^{2}$ & $\begin{array}{c}\text { Adjusted } \\
\mathrm{R}^{2}\end{array}$ & $\begin{array}{c}\mathrm{R}^{2} \\
\text { Change }\end{array}$ & $\mathrm{F}$ & $\begin{array}{c}\text { Sig- F } \\
\text { Change }\end{array}$ \\
\hline Step 1 control variables & 0.208 & 0.186 & 0.017 & $4.9^{*}$ & 0.027 \\
\hline $\begin{array}{l}\text { Step 2 control variables, privacy concern, } \\
\text { Big Five personality traits }\end{array}$ & 0.347 & 0.302 & 0.143 & $4.8^{* * *}$ & 0.000 \\
\hline $\begin{array}{l}\text { Step 3 control variables, privacy concern, } \\
\text { Big Five personality traits, impulsivity. }\end{array}$ & 0.461 & 0.417 & 0.114 & $15.3^{* * *}$ & 0.000 \\
\hline
\end{tabular}

